\title{
Biological Study of Jasmine Bud Worm, Hendecasis duplifascialis Hampsn. (Pyraustidae: Lepidoptera) from India
}

\author{
T. Krishna Chaitanya* and K. Kumar
}

Department of Agricultural Entomology and Nematology, Pandit Jawaharlal Nehru College of Agriculture and Research Institute, Karaikal, U. T. of Puducherry - 609602, India

*Corresponding author

\section{A B S T R A C T}

\section{Keywords}

Jasminum sambac,

Biology, Hendecasis

duplifascialis

Article Info

Accepted:

21 May 2018

Available Online:

10 June 2018
The bud worm, Hendecasis duplifascialis Hampsn is one of the major pests of jasmine, Jasminum sambac. The biology of budworm, H. duplifascialis was studied and found that the incubation period, total larval and pupal period were $3.40 \pm 0.23,11.60 \pm 1.30$ and $5.80 \pm 0.19$ days respectively. The longevity of male and female moths was $3.10 \pm 0.23$ and $4.10 \pm 0.31$ days respectively. The total life cycle for male and female moths was found to be $23.90 \pm 1.95$ and $24.90 \pm 2.03$ days respectively. It was also observed that the longevity of female moth was longer compared to the male.

\section{Introduction}

Jasmine (Jasminum sambac Aiton.) is one of the most important fragrant flower crops grown commercially for loose flowers. Jasmine buds are used for making garlands, bouquets, decorating women's hair, for religious offerings and for the production of perfumed oils and attars.

The flowers and other parts of the plant also find a place in useful medicines (Ramadas et al., 1985). The term jasmine is derived from the Arabic Persian word "Yasmin" with a meaning of "gift from god". In Tamil Nadu, $J$. sambac is cultivated in the districts of Madurai, Ramanathapuram, Kanyakumari, Tirunelveli, Dindugal, Coimbatore and Salem
(Jayachandran, 2001). There are about 50 different insect pest species belonging to more than eight orders harbour the varied microhabitats of the jasmine plants. The most devastating pest of jasmine is bud worm, $H$. duplifascialis.

The budworm, $H$. duplifascialis, was first reported in 1896 by Hampson in West Africa, India, Ceylon and David (1958) recorded in South India and Delhi. Lanfang et al., (2007) reported that the jasmine budworm, $H$. duplifascialis was widely distributed in all jasmine planting areas in Yuanjiang, with jasmine as the only host species. It occurred from April to October, with the ovipositional peaks in July, August and September. Knowledge of the biology of insect pests is a 
prerequisite for pest management. A successful management plan requires information about a species biology including its diet and lifecycle, how it interacts with the environment and with other species as well as species behaviour can be manipulated to prevent or reduce yield losses.

\section{Materials and Methods}

The larvae collected from the field (Fig. 1) on Jasminum sambac was introduced on the potted plants of $J$. sambac under greenhouse condition and cultured for the experiment. The pupae were collected and kept in petri plates. These plates were transferred inside the adult emergence/oviposition cage $(60 \times 45 \times 45 \mathrm{~cm})$. Ten per cent sugar solution with cotton swab was provided in penicillin vial as food to the adults.

Fresh unopened branches with buds were placed in a $250 \mathrm{ml}$ conical flask filled with water and plugged with cotton swab so as to keep the buds fresh and placed inside the oviposition cage. The moths on emergence were allowed for oviposition on the buds. Fresh branches with few buds were provided as a feed to the larvae as and when required. This culture was utilised for further studies.

Ten pairs were released inside a rearing cage $(60 \times 45 \times 45 \mathrm{~cm})$ and allowed for mating and oviposition. These moths were carefully observed at frequent intervals. The time interval between emergence and first oviposition gave the mating and preoviposition period and the time between the first and last oviposition gave the oviposition period.

A pair of male and female moths were confined in a five litre plastic container (diameter $10 \mathrm{~cm}$ ) soon after emergence. Inside the plastic container, branches having unopened buds of $J$. sambac were placed in a
$100 \mathrm{ml}$ conical flask filled with water and plugged with cotton. Ten per cent sugar solution was provided as a feed and the container was covered with a muslin cloth. Similar conditions were made for ten pairs of adults. After $48 \mathrm{hr}$, the buds were removed and the number of eggs laid was counted. The percentage hatchability was worked out from the total number of eggs laid and the number of larvae hatched. The neonate larvae were closely observed from hatching to pupation. Ten neonate larvae were observed and the number of days was recorded to find the larval and pupal periods. The moths on hatching from ten pupae were observed closely by maintaining them in a rearing cage with ten per cent sugar solution as a feed and the adult longevity was worked out in days (Suganthi et al., 2006).

\section{Results and Discussion}

The results on the biology of budworm, $H$. duplifascialis was given in Table 1. It was found that the eggs are laid singly in and surrounding the bud. The egg (Fig 2) was white in colour and the incubation period was found to be $3.40 \pm 0.23$ days. The larvae were pale green in colour (Fig. 2a). There were five larval instars with the mean duration of the $1^{\text {st }}$, $2^{\text {nd }}, 3^{\text {rd }}, 4^{\text {th }}$ and $5^{\text {th }}$ instars of $2.80 \pm 0.19,2.20$ $\pm 0.19,1.20 \pm 0.19,2.80 \pm 0.35$ and $2.60 \pm$ 0.38 days respectively.

The total larval period was $11.60 \pm 1.30$ days. The larvae pupate by spinning a cocoon at the junction of petiole and leaf blade. The average pupal (Fig. 4a) period was $5.80 \pm 0.19$ days. The adult moths (Fig. 5a) were active and fed with sugar solution for laying the eggs. The longevity of the male and female moths was $3.10 \pm 0.23$ and $4.10 \pm 0.31$ days respectively. The total life cycle were $23.90 \pm 1.95$ and $24.90 \pm 2.03$ days for male and female moths respectively and found that the longevity of female was higher compared to the male. 
Fig.1 Experimental field layout

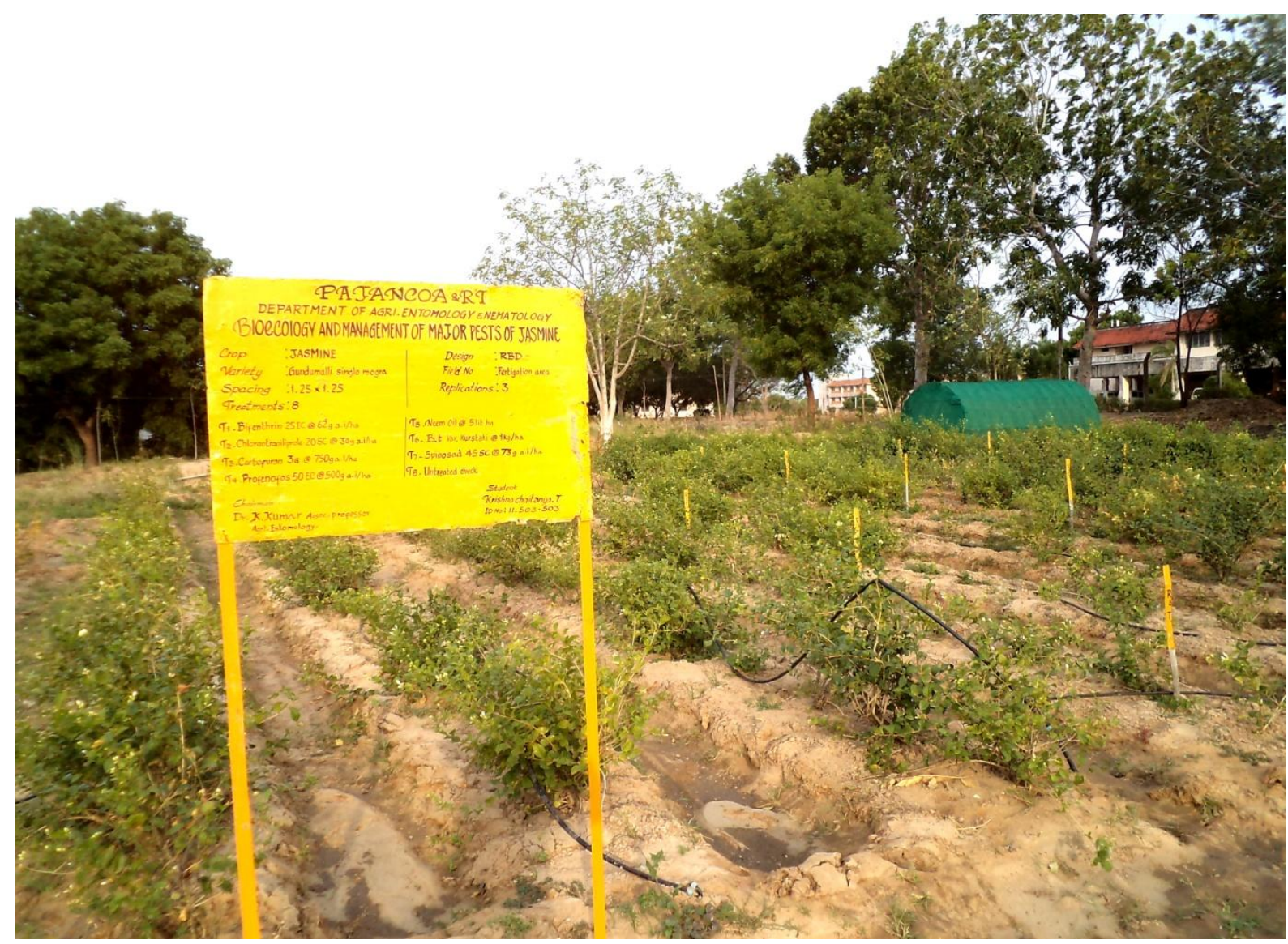

Fig.2 Damage symptom of jasmine budworm, Hendecasis duplifascialis (Hampsn.)

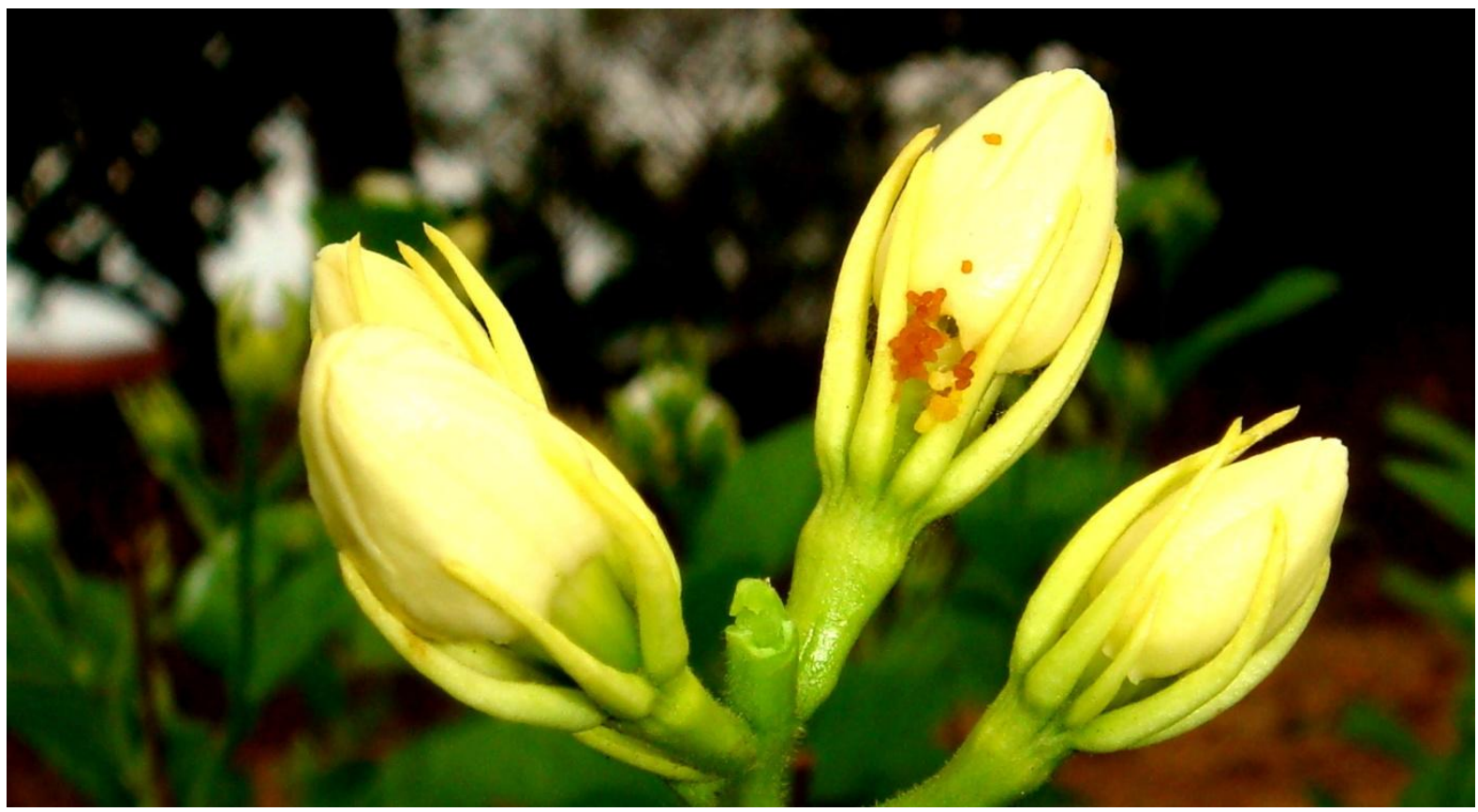


Fig.3 a, Egg b, Larva c, Pupa d, Adult
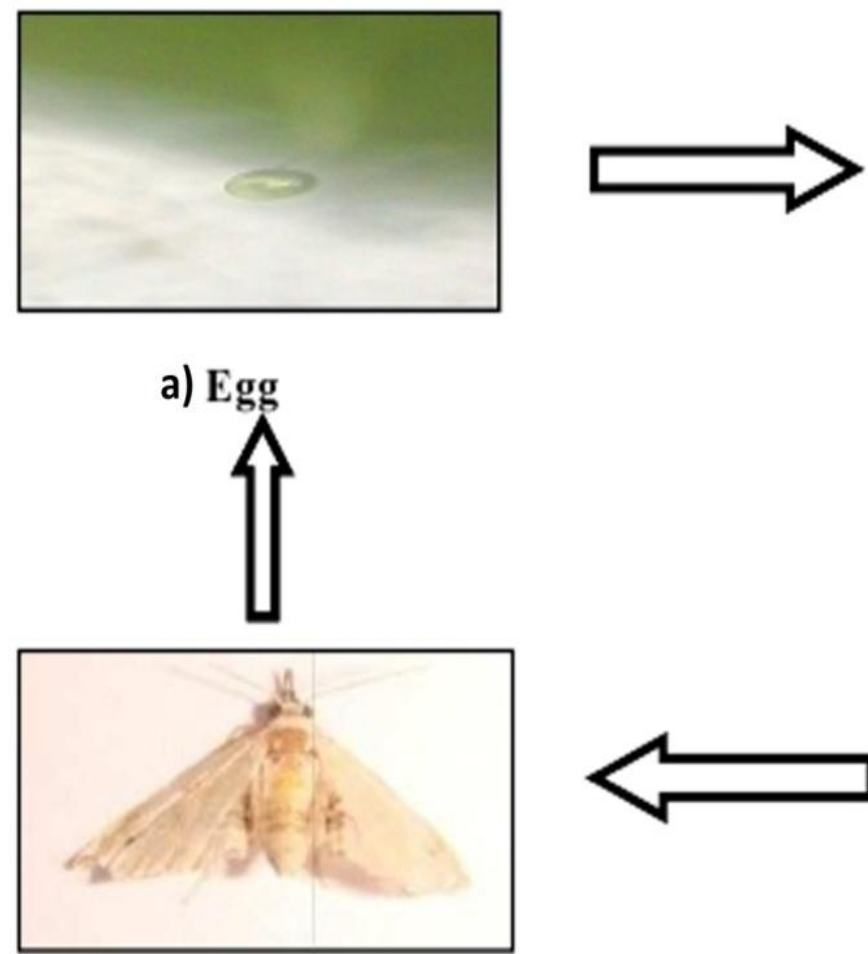

d)Adult

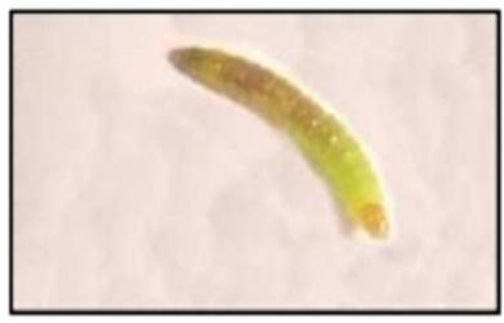

b) Larva

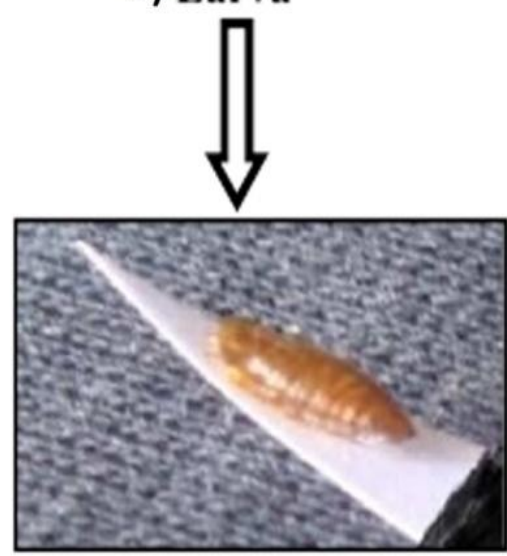

C) Pupa

Table.1 Biology of budworm, Hendecasis duplifascialis (Hampsn.) under laboratory condition

\begin{tabular}{|l|l|l|}
\hline SI. No. & Stages of Hendecasis duplifascialis & $\begin{array}{l}\text { Mean No. of Days } \pm \text { SE } \\
\text { (Mean of } 2 \text { replications) }\end{array}$ \\
\hline 1. & Incubation period & $3.40 \pm 0.23$ \\
\hline 2. & Larval period (instar wise) & \\
\hline a & I instar & $2.80 \pm 0.19$ \\
b & II instar & $2.20 \pm 0.19$ \\
c & III instar & $1.20 \pm 0.19$ \\
d & IV instar & $2.80 \pm 0.35$ \\
e & V instar & $2.60 \pm 0.38$ \\
\hline & Total larval period & $11.60 \pm 1.30$ \\
\hline 3. & Pupal period & $5.80 \pm 0.19$ \\
\hline 4. & Adult longevity & \\
a & Male & $3.10 \pm 0.23$ \\
b & Female & $4.10 \pm 0.31$ \\
\hline 5. & Total duration of the life cycle & \\
a & Male & $23.90 \pm 1.95$ \\
b & Female & $24.90 \pm 2.03$ \\
\hline
\end{tabular}


The biology of jasmine budworm, $H$. duplifascialis, and the incubation period, total larval and pupal period was found to be $3.40 \pm 0.23,11.60 \pm 1.30$ and $5.80 \pm 0.19$ days respectively. The total life cycle for male and female moths was found to be $23.90 \pm 1.95$ and $24.90 \pm 2.03$ days respectively (Table 1 ). It was also observed that, in case of budworm, $H$. duplifascialis the longevity of female moth was higher compared to the male. Lanfang et al., (2007) indicated that the egg, larva, pupa and adult period of $H$. duplifascialis lasted for $3.05,11.95,5.05$ and 4.95 days respectively. The total lifecycle lasted for 21.05 days with 10 to 11 overlapping generations in seven months. The present findings are in accordance with the above findings.

\section{References}

David, S.K. 1958. Insects and mites affecting jasmine in Madras state. Madras Agric. J., 45: 146-150.

Hampson, G.F. 1896. The fauna of British India including Ceylon and Burma.
Moths. IV. Dr. W. Junk Publishers. The Hague, pp. 594.

Jayachandran, R. 2001. Malligai cultivation. Valarum Velanmai, Tamil Nadu Agriculture University, Coimbatore. pp. 22-24.

Lanfang, G., T. Chayopas, S. Srikacha, P. Ratanasatien, J. Lerksunkate, S. Thothong and P. Kienmeesuke. 2007. Biology of jasmine flower borer, Hendecasis duplifascialis Hampson. Entomology and Zoology Gazette, 23(3): 158-177.

Ramadas, S., G.B. Peter and S. Muthuswami. 1985. Jasmine In: Commercial flowers (eds), T.K. Bose and L.P. Yadav. Naya Prakash Publishers, Calcutta, India. pp. 487-517.

Suganthi, A., S. Chandrasekaran and A. Regupathy. 2006. Pheromone release behaviour of jasmine budworm, Hendecasis duplifascialis Hampson. (Pyraustidae: Lepidoptera). Indian Journal of Entomology, 3(3): 236-240.

\section{How to cite this article:}

Krishna Chaitanya T. and Kumar K. 2018. Biological Study of Jasmine Bud Worm, Hendecasis duplifascialis Hampsn. (Pyraustidae: Lepidoptera) from India. Int.J.Curr.Microbiol.App.Sci. 7(06): 2884-2888. doi: https://doi.org/10.20546/ijcmas.2018.706.339 